\title{
Anterior Tongue Mucoepidermoid Carcinoma
}

National Cancer Institute

\section{Source}

National Cancer Institute. Anterior Tongue Mucoepidermoid Carcinoma. NCI Thesaurus.

Code C6250.

A mucoepidermoid carcinoma arising from the minor salivary glands in the anterior tongue. 